\title{
New insights in swine model of ventricular tachycardia using quantitative myocardial tissue characterization
}

\author{
Sébastien Roujol ${ }^{1 *}$, Tamer A Basha ${ }^{1}$, Cory M Tschabrunn ${ }^{1}$, Kraig V Kissinger ${ }^{1}$, Mark E Josephson ${ }^{1}$, \\ Warren J Manning ${ }^{1,2}$, Elad Anter ${ }^{1}$, Reza Nezafat ${ }^{1}$ \\ From 18th Annual SCMR Scientific Sessions \\ Nice, France. 4-7 February 2015
}

\section{Background}

Ventricular tachycardia (VT) is often responsible for sudden cardiac death and is generally triggers by the presence of reentry circuits related to a chronic myocardial scar. We have recently developed a novel swine model of VT, where sustained monomorphic reentrant VT can be induced in all animals. This new model offers exciting opportunities for better understanding the underlying substrate of VT, as well as for the development of new mapping and ablation strategies. In this study, we sought to provide in-vivo tissue characterization of this model using myocardial tissue characterization techniques of $T_{1}, T_{2}$ and high-resolution LGE.

\section{Methods}

A novel swine model of reentrant VT was induced in 11 Yorkshire swine by $180 \mathrm{~min}$ balloon occlusion of the mid left anterior coronary artery. Each animal underwent an in-vivo CMR exam using a $1.5 \mathrm{~T}$ Philips scanner at 52 \pm 13 days after infarction, followed by an electrophysiology study with programmed stimulation to assess for VT inducibility. During imaging, each animal was sedated, intubated and mechanically ventilated. Native $T_{1}$ mapping using MOLLI (1) and $\mathrm{T}_{2}$ mapping (2) were performed and followed by bolus injection of $0.2 \mathrm{mmol} / \mathrm{kg}$ of gadobenate dimeglumine and post-contrast $\mathrm{T}_{1}$ mapping using MOLLI. All these parametric sequences used ECG-triggered single shot acquisitions with balancedSSFP imaging readout and the following parameters: $\left(\mathrm{TR} / \mathrm{TE}=4.3 / 2.1 \mathrm{~ms}\right.$, flip angle $=35^{\circ}\left(\mathrm{T}_{1}\right.$ mapping $) / 85^{\circ}\left(\mathrm{T}_{2}\right.$ mapping), FOV $=360 \times 276 \mathrm{~mm}^{2}$, voxel size $=2 \times 2 \mathrm{~mm}^{2}$, slice thickness $=8 \mathrm{~mm}, 10$ slices $\left(\mathrm{T}_{1}\right.$ mapping $) / 5$ slices $\left(\mathrm{T}_{2}\right.$ mapping), SENSE factor $=2$ ). Finally, high resolution LGE (3) was performed using a free breathing navigator-gated inversion recovery gradient echo sequence with the following parameters (TR/TE $/ \alpha=6.5 / 3.0 \mathrm{~ms} / 25^{\circ}$, FOV $=270 \times 270 \times 112 \mathrm{~mm}^{3}$, voxel size $=1 \times 1 \times 1 \mathrm{~mm}^{3}$, compressed sensing factor $=4$ ). All imaging was performed in the short axis orientation. Analysis was performed offline using an in-house platform. The areas of enhancement in LGE data was used to visually guide a manual segmentation of the corresponding areas in all $\mathrm{T}_{1}$ and $\mathrm{T}_{2}$ maps. A similar approach was used to delineate an area of healthy myocardium all $T_{1}$ and $T_{2}$ maps. $T_{1} / T_{2}$ maps with artifacts were discarded from the analysis. Native $T_{1}$ times and $\mathrm{T}_{2}$ times are reported for both "remote area" and "area of enhancement".

\section{Results}

Sustained reentrant VT could be induced in all animals. In-vivo CMR revealed that areas with elevated native $T_{1}$ times and $T_{2}$ times were in good agreement with areas depicting reduced post-contrast $\mathrm{T}_{1}$ times and enhancement in LGE (Figure 1). Over all animals, area with enhancement as defined by LGE had higher native $\mathrm{T}_{1}$ times $(1276 \pm 45$ vs. $1047 \pm 29, \mathrm{p}<0.001)$ and higher $\mathrm{T}_{2}$ times $(85 \pm 6$ vs. $52 \pm 4, \mathrm{p}<0.001)$ than remote area (Figure 2 ).

\section{Conclusions}

In this swine model of reentrant VT, areas of LGE hyperenhancement are associated with elevated native $\mathrm{T}_{1}$ times and $\mathrm{T}_{2}$ times. 

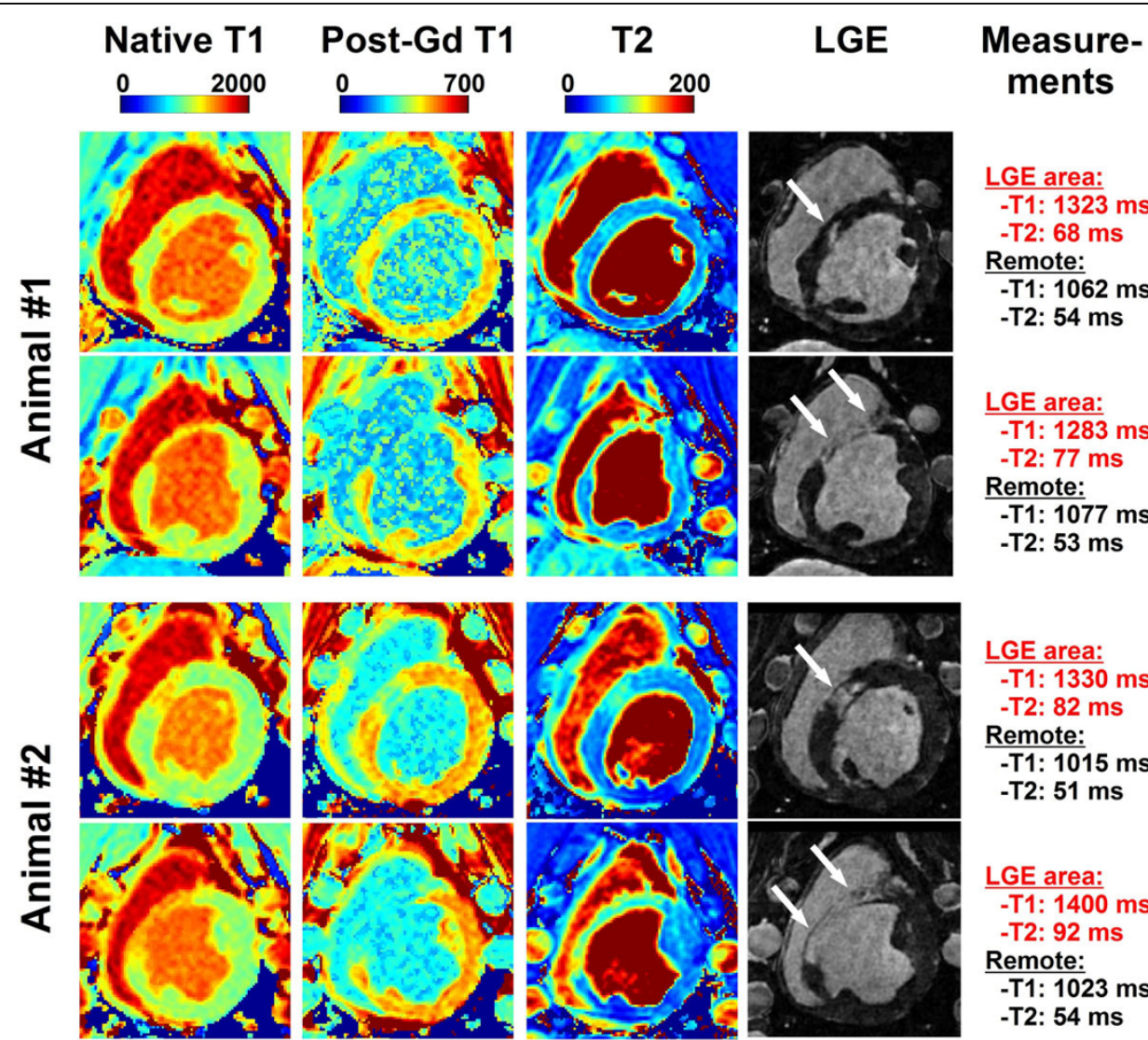

LGE area:

-T1: $1323 \mathrm{~ms}$

-T2: $68 \mathrm{~ms}$

Remote:

-T1: $1062 \mathrm{~ms}$

-T2: $54 \mathrm{~ms}$

LGE area:

-T1: $1283 \mathrm{~ms}$

-T2: $77 \mathrm{~ms}$

Remote:

-T1: $1077 \mathrm{~ms}$

-T2: $53 \mathrm{~ms}$
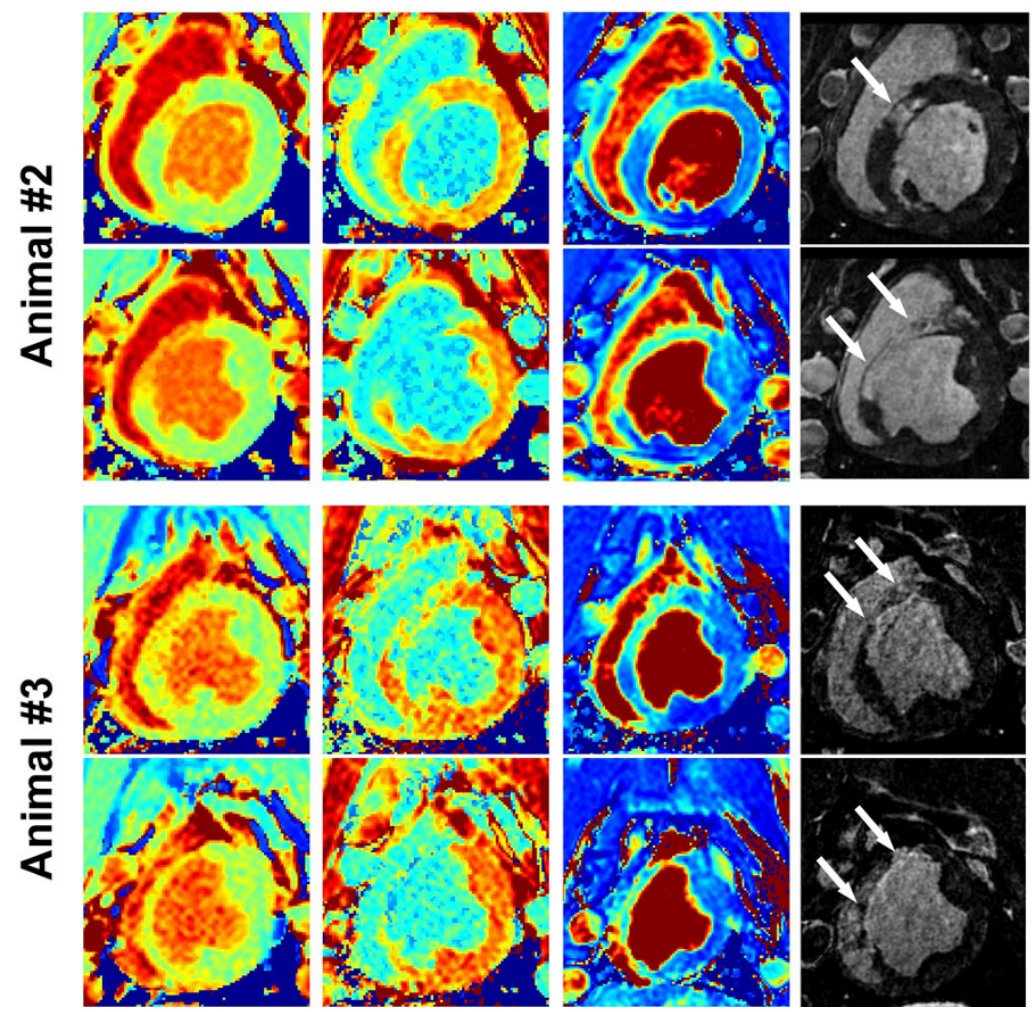

LGE area:

-T1: $1330 \mathrm{~ms}$

-T2: $82 \mathrm{~ms}$

Remote:

-T1: $1015 \mathrm{~ms}$

-T2: $51 \mathrm{~ms}$

LGE area:

-T1: $1400 \mathrm{~ms}$

-T2: $92 \mathrm{~ms}$

Remote:

-T1: $1023 \mathrm{~ms}$

-T2: $54 \mathrm{~ms}$

Figure 1 Example of native $T_{1}$ maps, post-contrast $T_{1}$ maps (post-Gd $T_{1}$ ), $T_{2}$ maps and LGE obtained in 3 swine. Elevated native $T_{1}$ times and $T_{2}$ times can be observed in the area of LGE enhancement.
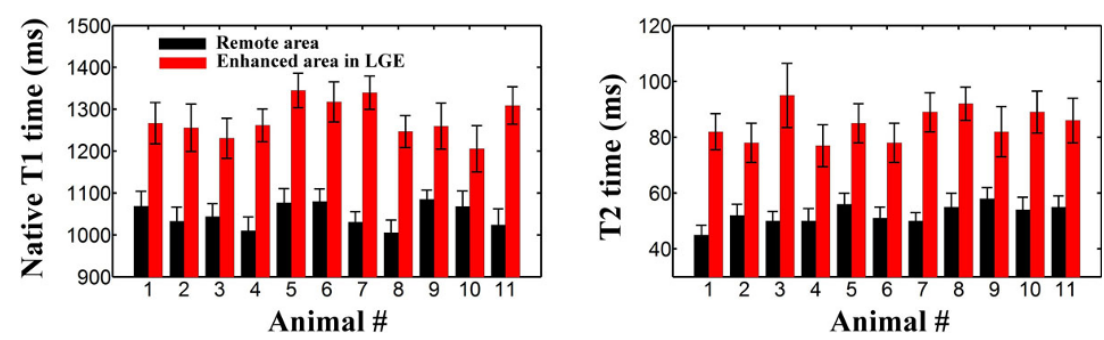

Figure 2 Native $T_{1}$ times and $T_{2}$ times measured in area of enhancement in LGE (red) and in remote area (black). Higher $T_{1}$ times and $T_{2}$ times were obtained in area of enhancement in LGE $(p<0.001)$. 


\section{Authors' details}

'Department of Medicine, BIDMC / Harvard Medical School, Boston, MA,

USA. ${ }^{2}$ Radiology, BIDMC / Harvard Medical School, Boston, MA, USA.

Published: 3 February 2015

\section{References}

1. Messroghli : MRM 2004

2. Akçakaya : MRM 2014.

3. Akçakaya : Radiology 2014.

doi:10.1186/1532-429X-17-S1-Q132

Cite this article as: Roujol et al.: New insights in swine model of ventricular tachycardia using quantitative myocardial tissue

characterization. Journal of Cardiovascular Magnetic Resonance 201517

(Suppl 1):Q132.

Submit your next manuscript to BioMed Central and take full advantage of:

- Convenient online submission

- Thorough peer review

- No space constraints or color figure charges

- Immediate publication on acceptance

- Inclusion in PubMed, CAS, Scopus and Google Scholar

- Research which is freely available for redistribution

Submit your manuscript at www.biomedcentral.com/submit
() BioMed Central 